\title{
TRANSVAGINAL PELVIC SCAN ALONG WITH SONOHYSTERO- SALPINGOGRAPHY IN EVALUATION OF INFERTILITY
}

Narayani. B.H ${ }^{1}$, Shukla Shetty².

\section{HOW TO CITE THIS ARTICLE:}

Narayani. B.H, Shukla Shetty. "Transvaginal pelvic scan along with sonohystero-salpingography in evaluation of Infertility". Journal of Evolution of Medical and Dental Sciences 2013; Vol2, Issue 28, July 15; Page: 5251-5256.

\begin{abstract}
Background and Objective: Infertility is a common complaint during the reproductive age group and accounts for much medical and surgical intervention. Sonohystero-salpingography is a cost effective, safe, non-invasive and painless procedure to visualize the female pelvic organs in the evaluation of infertility. The purpose of this study is to find out the factors responsible for female infertility in single sitting using non-invasive, painless and acceptable procedures. METHODS: 50 infertile women were included for the study. After taking consent, all the women were subjected to TVS along with sonohystero-salpingography in the same sitting between 7th and 11th day of menstrual. RESULTS: The factors responsible for infertility namely uterine, ovarian and tubal detected compared with other standards studies. Interpretation and Conclusion: TVS along with sonohystero-salpingography can be used as primary diagnostic tool in the overall assessment of factors responsible for infertility. It is simple safe, non invasive and avoid unnecessary diagnostic procedures.
\end{abstract}

KEY WORDS: Infertility, Sonohystero-salpingography, Uterine factors, Tubal factors, Ovarian factors

INTRODUCTION: Various diagnostic procedures are available to evaluate the anatomy and function of the ovaries, uterus and the fallopian tubes. Ultrasound examination for the anatomy of the uterus, tubes and ovaries may give sufficient information and can be modality of investigation over the other. ${ }^{1}$ The aim of the study was to evaluate all women who presented with primary or secondary infertility and to find out uterine, tubal and ovarian factors responsible for female infertility with the use of ultrasound.

METHODS: The present study was carried out on 50 infertile women who attended Obstetric and Gynecology Departments of the Hospitals attached to J.J.M. Medical College during the period from November 2005 to September 2007.

Inclusion Criteria: Primary and Secondary infertile women in the reproductive age group.

Exclusion criteria: Patients having active pelvic infection, active vaginal bleeding, malignancy of the genital tract, and abnormal semen analysis of the Husband. All eligible patients were properly counseled and gave informed consent before entry into the study. Detailed menstrual, obstetric and medical histories of each patient were obtained and general physical, systemic and gynecological examination was performed. Relevant investigations were performed according to clinical findings. All the 50 patients were subjected to Trans-vaginal scan along with saline infusion Sonohysterosalpingography in the same setting to visualize the uterine contour, contents, ovaries and the fallopian tubal patency. This procedure was performed between 7 th and 11th day of the menstrual 
cycle. Initially the patients were evaluated with an abdominal transducer. Then TVS was done to note endometrial thickness, uterine or ovarian abnormality and later normal saline 20-30 ml injected into the uterus through Foley's Catheter 8 French to know the tubal patency and to look for endometrial polyp. The right and left ovarian fossae, paracolic gutters and the pouch of Douglas was visualized. Flow of fluid and air - "Turbulence" was looked for in the region of right and left ovarian fossae and this "turbulence"- "The waterfall sign" was taken as patency of the respective fallopian tube. Later the cul de sac was also visualized to look for free fluid. (Fig 1 \& 2)

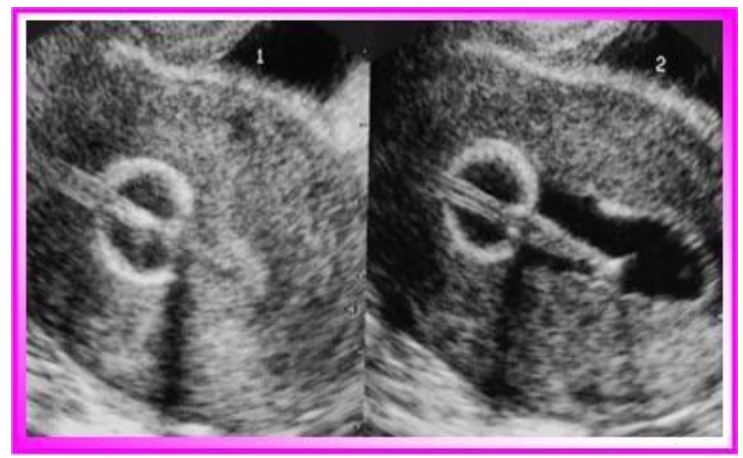

Fig 1: Normal Uterus. TVS (Sagittal View) showing the distention of endometrial cavity after instillation of normal saline

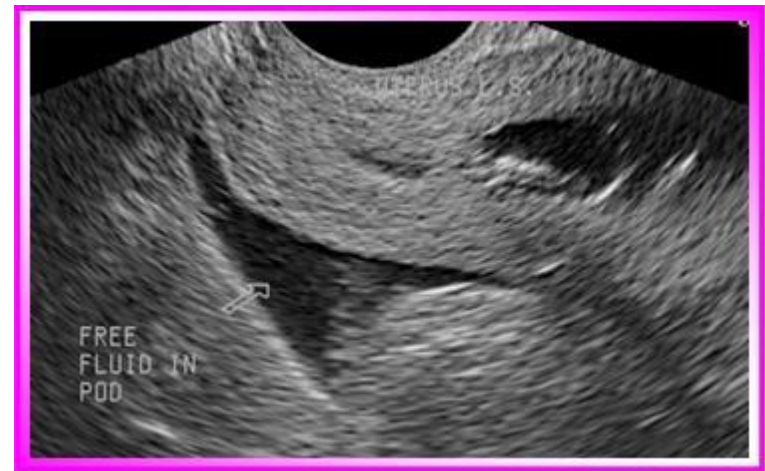

Fig 2: Normal Uterus - TVS (Sagittal View) showing the free fluid in POD suggestive of tubal patency

RESULTS: In the study 22 cases (44\%) were in the age group of 20-24 years. 23 cases (46\%) were in the age group of $25-29$ years, 3 cases (6\%) were in the age group of $30-34$ years. $4 \%$ cases were in age group above 35 years. The minimum age of the patient was 20 years and the maximum age of the patient was 38 years. The mean age of the patient was 25.18 years (range 20-38 years).

In this study of infertile women overall incidence of primary infertility was found to be $68 \%$ (34 cases) and secondary infertility was 32\% (16 cases).In the present study 20 cases (40\%) were of 1-4 years of infertility. 26 cases (52\%)were having 5-9 years of infertility. 4 cases (8\%) were having 10-12 years (range-1.5-12 years).In the present study menstrual pattern was normal in 18 cases (36\%), 14 cases (28\%) presented with oligomenorrhea, 10 cases (20\%) presented with menorrhagia, 3 cases (6\%) presented with amenorrhea, 2 cases (4\%) presented with hypomenorrhea, 3 cases (6\%) presented with metrorrhagia. Most common abnormal menstrual pattern was Oligomenorrhea. By using TVS uterus was found to be normal size in 43 cases (86\%) 
while in 7 cases $(14 \%)$ it was enlarged. In this study 11 cases (22\%) had endometrial thickness of 3.1-5.9 mm, 34 cases (68\%) had thickness of 6.0-12.0 mm. More than $12 \mathrm{~mm}$ was seen in 3 cases $(6 \%)$ and endometrial echo was absent in 2 case (4\%). Mean endometrial thickness was $8.5 \mathrm{~mm}$. The range was $3.1-14.6 \mathrm{~mm}$ in 48 cases, excluding 2 cases with absent endometrial echo. In the present study transvaginal scan revealed normal ovaries in 38 cases $(76 \%)$ on right side and 36 cases (72\%) on left side and bilaterally enlarged ovaries seen in 8 cases (16\%). Bilaterally small ovaries were seen in 2 cases (4\%). Ovaries on right side were replaced by tubo-ovarian mass in 2 cases (4\%) and on left side in 4 cases (8\%). Study also shown that polycystic ovary was seen in 8 cases (16\%). Dominant follicle in any one ovary was present in 29 cases (58\%) and was absent in 21 cases (42\%). (Table i) (Fig 3)

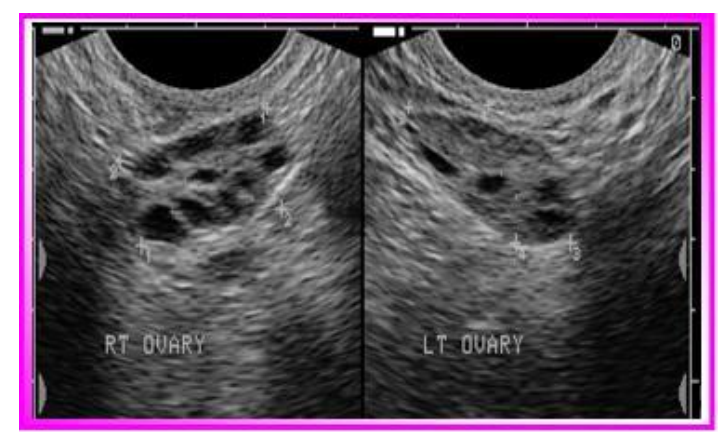

Fig 3: TVS (Sagittal View) showing bilateral enlarged ovaries with multiple follicles diffusely distributed throughout the parenchyma suggestive of PCOD

Table - I

\begin{tabular}{|l|l|l|}
\hline & PCOS & T.0. Mass \\
\hline Present study & $16 \%$ & $4-8 \%$ \\
\hline Prasad S4 (1999) & $8.80 \%$ & - \\
\hline Rahman, Sinha2 (2002) & $13 \%$ & $8 \%$ \\
\hline
\end{tabular}

Adnexal abnormality in infertile women

In the present study no uterine pathology was identified in 40 cases (80\%) while pathology was identified in 10 cases (20\%) submucous fibroid ( Fig 4 ) was seen in 2 cases (4\%) multiple fibroids were seen in 2 cases (4\%), posterior wall fibroid seen in 1 case (2\%), intramural fibroid seen in 1 case $(2 \%)$, adhesion were seen in 1 case $(2 \%)$, combination of adhesion and intramural fibroid seen in 1 case (2\%),polyp seen in 2 cases (4\%). (Table ii) 


\section{ORIGINAL ARTICLE}

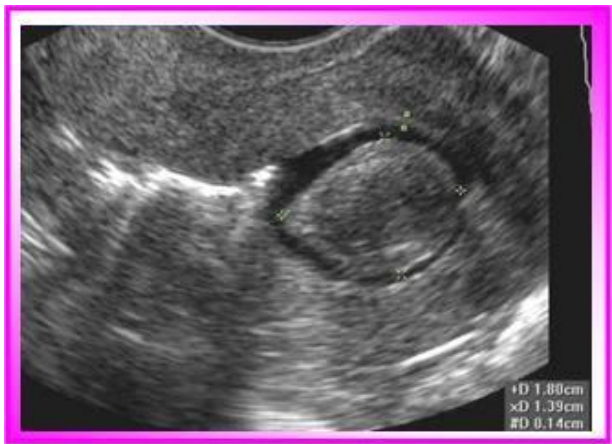

Fig4: TVS (Sagittal View) showing an submucous (intra cavitary) Fibroid

Table - II

\begin{tabular}{|l|l|}
\hline Study & Fibroids (\%) \\
\hline Present study & 12 \\
\hline Prasad S4 & 4.40 \\
\hline Mitri FF5 & 23.00 \\
\hline Rahman, Sinha 2 & 4.5 \\
\hline
\end{tabular}

Fibroids in infertile women

Fluid in Cul de sac was demonstrated in 46 cases (92\%) and in 4 cases (8\%) it was absent. Bilateral patent tubes were seen in 38 cases (76\%).In this study 12 cases (24\%) had minor complaints like lower abdominal pain. 38cases (76\%) did not have any complaints. 1 case (2\%) had complication like peritonitis and other 49 cases did not have any complication. In this study primary infertility patients showed fibroid and or polyp in 5 cases $(14.7 \%)$ while in secondary infertility patients it was 4 cases (25\%). Even though the incidence of fibroids and or polyp is increased in secondary infertility but is statistically insignificant (X2 $=0.24, \mathrm{P}>0.05)$. Present study revealed PCOS in patients with age $\leq 25$ years in 5 cases $(18.5 \%)$ and in patients with age $>25$ years it was present in 3 cases (13\%), however it is statistically insignificant ( $p>0.05)$ Fibroids was present in 2 cases $(7.4 \%)$ of the patient with age $<25$ years and was present in 7 cases $(30.4 \%)$ in patients with age $>25$ years it revealed the incidence of fibroids increased with age of the patient and it was statically significant (X $2=4.46 \& \mathrm{P}<0.05$ ) In the present study ovarian asymmetry with dominant follicle in any one ovary with late proliferate endometrium seen in 29 cases (58\%.) Bilateral symmetrical ovaries with no follicular activity and thin endometrium seen in 11 cases (22\%). Bilaterally enlarged ovaries with cysts arranged in necklace pattern (PCOS) with different patterns of endometrium seen in 8 cases $(16 \%)$ comparable to study by Prasad S $4(8.8 \%)$ is almost double whereas it is comparable to study by Rahman, Sinha ${ }^{2}$ ( $13 \%$ ). Bilateral small ovaries with absent endometrial echo in 2 cases $4 \%$. (Table iii) 


Table - III
\begin{tabular}{|l|l|l|}
\hline Ovarian Morphology and follicular activity & $\begin{array}{l}\text { Present } \\
\text { Study (\%) }\end{array}$ & $\begin{array}{l}\text { Rahman , } \\
\text { Sinha 2 (\%) }\end{array}$ \\
\hline $\begin{array}{l}\text { 1) Ovarian asymmetry with dominant follicle in one } \\
\text { ovary }\end{array}$ & 58 & 62 \\
\hline $\begin{array}{l}\text { 2) Bilateral symmetrical ovaries with no follicular } \\
\text { activity }\end{array}$ & 22 & 21.5 \\
\hline 3) Bilateral enlarged ovaries with no follicular activity & 16 & 13 \\
\hline $\begin{array}{l}\text { 4) Primary ovarian failure } \\
\text { Total }\end{array}$ & 4 & 3.5 \\
\hline
\end{tabular}

Follicular activity in infertile women

DISCUSSION: Fertility peaks by 25 years of age and 1/3rd of women are no longer fertile by 40 years of age..$^{3}$ since the fertility of women decrease progressively with age particularly after 30 years, so earlier the patient is investigated for infertility the better the chance of success. Present study shows that trans-vaginal scan along sonohystero-salpingography done in single sitting in the infertility work up gives overall assessment of women including uterine factors, ovarian factors, tubal factors and also endocrine factors (hormonal status). 2,4,5,6

Which are comparable with other investigation modalities for tubal patency like hysterosalpingography (HSG), laparoscopy ${ }^{2,4,5,6}$. Whereas trans-vaginal scan along with sonohysterosalpingography can be used a simple, non-invasive, with no exposure to radiation in the evaluation of infertility patient. Thus, we can save a large number of unnecessary invasive diagnostic procedure, money, and discomfort to the patient. 7,8

Hence It is recommended that TVS along with sonohystero-salpingography should be used as primary investigation modality in infertile women after evaluating the partner.

\section{BIBLOGRAPHY:}

1. Gunesheela S, Biliangady RH. Evaluation of Fallopian tube in Infertility. In: Rao KA edt., The Infertility manual. 2nd edn. New Delhi: Jaypee Brothers medical publishers (P) Ltd, 2004: p.204- 05.

2. Rahman M, Sinha DK. A cost effective approach in the evaluation of Female infertility. J of Obst \& Gyn of India 2002; 52(1): 105-107.

3. Tietze C. Reproductive span and role of reproduction among Hutterite Women. Fertil steril. 1957: 8; 89-97.

4. Prasad S: Tubal evaluation by transvaginal sonosalpingography - A comparative study. Ob gyne today 1999: volume 4; 2.

5. Mitri FF, Andronikou AD, Perpinyal S, Hofmeyr GJ and Sonnedecker EWW. A clinical comparison of Sonographic hydrotubation and Hystero salpingography. British J of Obst \& Gyne 1991; 98:1031-1036. 


\section{ORIGINAL ARTICLE}

6. Urman B, Yakin K. Ovulatory disorders and infertility. The Journal of reproductive medicine 2006; 51(4): 267-82.

7. Dessole. Side effects and complications of Sonohysterography. Fertil steril 2003; 80:3.

8. Onah HE, Ezike, Mgbor SO. Saline sonohystero-salpingographic findings in infertile Nigerian women J. Obstet Gyneco 2006; 26(8): 788-90

\section{AUTHORS:}

1. Narayani.B.H

2. Shukla Shetty

\section{PARTICULARS OF CONTRIBUTORS:}

1. Assistant Professor. Dept of OBG. Yenepoya Medical College

2. Professor. Dept of OBG. JJMMC, Davangere
NAME ADRRESS EMAIL ID OF THE CORRESPONDING AUTHOR:

Narayani. B. H,

Consultant in Fetal Medicine,

Mangalore Fetal Medicine Centre,

Kankanady, Mangalore.

Email: bandi_dd@yahoo.com

Date of Submission: 05/07/2013.

Date of Peer Review: 05/07/2013.

Date of Acceptance: 05/07/2013.

Date of Publishing: 15/07/2013 